\title{
Reconstitution of Spectrin-Deficient, Spherocytic Mouse Erythrocyte Membranes
}

\author{
STEPHEN B. ShOHET, Cancer Research Institute and Hematology Division, University \\ of California, San Francisco, San Francisco, California 94143
}

A B S T R A C T To study directly the role of spectrin in erythrocyte membrane function, we have designed a reconstituted membrane system using erythrocyte membranes from spectrin-deficient mice and purified spectrin from normal mice. The normal spectrin is inserted into the spectrin-deficient spherocytes by exchange hemolysis. Thereafter, raising the ionic strength and temperature reseals the cells and, with time, facilitates binding of the spectrin to the spectrindeficient membranes. The binding is apparently specific as shown by its dependence upon the concentration of undenatured spectrin and the concentration of salt used, as well as by the immunofluorescent appearance of the reconstituted cells after treatment with specific antispectrin antibody.

In terms of in vitro cellular behavior, the reconstituted preparations show marked changes in comparison to the untreated spherocytes. In particular, membrane stability, as measured by the reduction of myelin figure formation and lipid loss, is considerably enhanced. In addition, membrane fusion, which occurs readily with the untreated spherocytes, is virtually eliminated. Finally, the osmotic behavior of the native spherocytes is appreciably altered, such that the early phase of osmotically induced swelling, as measured in a highspeed stop-flow apparatus, is delayed and modified.

Taken together, these findings indicate specific roles for spectrin in the stabilization of the erythrocyte membrane, in the limitation of membrane fusion, and in the modulation of the membrane's response to osmotic stress.

\section{INTRODUCTION}

Spectrin is an unusual, very high molecular weight protein component of erythrocyte membranes (1). During the $12 \mathrm{yr}$ that have passed since its discovery, several important putative roles have been proposed for this polypeptide which accounts for at least $20 \%$ of

Received for publication 2.5 January 1.979 and in revised form 6 April 1.979. the total mass of the erythrocyte membrane, and which probably is found only in erythrocytes (2). Early observations of its tendency to form filaments - especially when combined with actin - and its apparently high axial ratio prompted analogies to muscle myosin and suggestions that spectrin might be part of a contractile or tension-generating system in the membrane $(3,4)$. Subsequently, it was shown that the spatial disposition of some external surface membrane markers, as well as intramembranous particles which appear to be linked to them, could be varied by antibody treatment of spectrin $(5,6)$. As spectrin is clearly located on the internal or cytoplasmic surface of the membrane (7), this observation added considerable credence to this view and suggested an extensive anchoring (or even organizational) role for this protein. Further, because spectrin is phosphorylated by a membrane kinase system in erythrocytes (8), and because a phosphatase has also been found in the membrane $(9,10)$, possible roles for a spectrin phosphorylation cycle in various energy-dependent membrane reactions have been suggested. Notably, it has been proposed that spectrin may be important in the maintenance of normal cell shape and deformability, and that the metabolic dependence of these physiologically important parameters may be directly or indirectly related to conformational changes in the molecule conferred by its phosphorylation state (11-14). Studies showing abnormalities of spectrin phosphorylation in several patients with hereditary spherocytosis give some support to this view $(15,16)$, although not all cases of spherocytosis demonstrate this phenomenon, and its specificity is not restricted to spherocytosis (17-19). Additionally, strong evidence for a structural role for spectrin can be found in the demonstration of "spectrin shells" of various abnormally shaped cells treated with nonionic detergents to extract virtually all of the membrane proteins other than spectrin and actin $(20,21)$. These residual spectrin shells maintain the abnormal shape of the original cell, and thus, suggest a specific architectural or scaffolding role for the spectrin-actin latticework. 
This suggestion is further supported by observations of close correlations between the in vitro conditions which cause changes in the extractability or aggregation state of spectrin, and conditions which induce sphering and loss of deformability of erythrocytes (22-24). Finally, the recent finding of marked spectrin deficiency in a strain of mice with severe hemolysis and hereditary spherocytosis again strongly suggests a role for spectrin in maintenance of normal cell shape (25). Because the cells of this mouse are extraordinarily unstable, a membrane-stabilizing role, as well as a shape-control role, has also been proposed for this molecule (26). The demonstration of spectrin-lipid interactions in purified liposome systems (27), of an apparent effect of spectrin in regulating the phospholipid assymetry of the membrane (28), and spectrin's known interactions with actin $(29,30)$, as well as its probable interactions with intermembranous particles and internal membrane proteins (6), all suggest mechanistic possibilities for these roles and lend credence to this view.

Unfortunately, all of these observations, perforce, have been indirect, and it has been difficult to assign unequivocally a functional role to this apparently important constituent of the erythrocyte membrane. In the current experiments, a system has been designed to examine directly some of the functions of spectrin in the erythrocyte membrane.

In brief, the technique of exchange hemolysis, previously developed for the insertion of sickle hemoglobin into normal cell membranes (31), has been adapted to insert spectrin within the membranes of spectrindeficient hereditary spherocytic mouse cells. Subsequently, binding of spectrin to the interior surface of these cells occurs when the ionic strength and temperature are raised for a sufficient period of time. This process, which is analogous to that described by Bennett and Branton for spectrin rebinding to spectrin-depleted inside-out human membrane vesicles (32), appears to show immunologic and biochemical specificity. Finally, profound changes in the behavior of these reconstituted cells occur after this binding, which appear to directly identify some functional roles for spectrin.

\section{METHODS}

Animal types and erythrocyte procurement. Homozygous $s p h / s p h$ spherocytic mice were a generous gift of Dr. Sheldon Bernstein of the Jackson Memorial Laboratories, Bar Harbor, Maine. Control mice consisted of the $\mathrm{WBB}_{6} \mathrm{~F}_{1}$ strain. This is the genetic background strain into which Dr. Bernstein introduced the $s p h / s p h$ gene (33) from the WB-Re--+/Sph and the C57B1 $-{ }_{6}-+$ Sph strains, and, except for that gene, represents exactly the same genetic background as the affected mice. Blood was obtained from both spherocytic and control mice by retro-orbital puncture with 2-mm internal diameter heparinized capillary tubes. Approximately $250 \mu$ l of blood could be repeatedly obtained from each animal without mortality by this technique. Samples were pooled, immediately chilled in ice, and washed once with phosphate-buffered saline $(\mathrm{PBS})^{1}$ to remove plasma and the bulk of leukocytes and platelets. Unfortunately, passage through cellulose columns or more thorough saline washing could not be used, as these refinements produced considerable hemolysis. Nevertheless, the simple washing procedure resulted in $<400$ leukocytes $/ \mathrm{mm}^{3}$ and $<6,000$ platelets $/ \mathrm{mm}^{3}$ at $30 \%$ hematocrit.

High-reticulocyte control blood was obtained by bleeding. Mice were bled $0.6-1.0 \mathrm{ml}$ on 3 successive days. $36 \mathrm{~h}$ after the last bleeding, reticulocyte-rich $(25-40 \%)$ blood was collected by exsanguination. A further enrichment to $\sim 80-90 \%$ was then obtained by centrifugation in small tubes in an angle head centrifuge at room temperature. Because the Sph mice were profoundly hemolytic with reticulocyte counts $>95 \%$, the control studies with normal mouse blood always used this reticulocyte-enriched preparation.

Preparation of purified spectrin for reconstitution studies. Washed erythrocytes were lysed in $25 \mathrm{vol}$ of iced $30 \mathrm{mosM}$ phosphate buffer, $\mathrm{pH} 7.8$, at $0^{\circ} \mathrm{C}$. The membranes were separated by centrifugation for $15 \mathrm{~min}$ at $45,000 \mathrm{~g}$, and washed three times with the iced lysis buffer. A small opaque button at the bottom of the tubes was discarded and the bulk of the membranes was resuspended in $0.1 \mathrm{mM}$ EDTA at $\mathrm{pH} 8$ and incubated $30 \mathrm{~min}$ at $37^{\circ} \mathrm{C}$ with gentle agitation. After prompt cooling, the residual membranes were separated from the extracted spectrin by ultracentrifugation at $80,000 \mathrm{~g}$ for $1 \mathrm{~h}$ at $4^{\circ} \mathrm{C}$. The resultant supernate was then concentrated to a small volume by dialysis against $20,000 \mathrm{~mol}$ wt polyethylene glycol followed by a second dialysis against $10 \mathrm{mM}$ Tris buffer, $\mathrm{pH}$ 7.4, with $1 \mathrm{mM}$ EDTA. Finally, the spectrin was separated from the majority of actin and small amounts of other contaminating membrane proteins by gel filtration on Sepharose 4B (Pharmacia Fine Chemicals, Div. of Pharmacia Inc., Piscataway, N. J.). During elution with $0.2 \mathrm{M}$ sodium chloride, which was monitored by absorbance at $280 \mathrm{~nm}$, spectrin was released from the column in the void volume. Approximately $30 \mathrm{mg}$ of spectrin could be obtained from 200 $\mathrm{cm}^{3}$ of mouse blood by this procedure.

When labeled spectrin was necessary, the same procedure was employed except that the whole erythrocytes were suspended in Krebs-Ringer bicarbonate buffer without phosphate at $\mathrm{pH} 7.8$ and incubated for $6 \mathrm{~h}$ with penicillin and streptomycin at $37^{\circ} \mathrm{C}$ to deplete intracellular phosphate stores. $20 \mathrm{mCi}$ of [ ${ }^{32} \mathrm{P}$ ]orthophosphoric acid/ml of packed erythrocytes was added, and the incubation was allowed to continue for an additional $18 \mathrm{~h}$. Subsequently, the cells were washed twice with isotonic PBS and the spectrin was extracted as just described.

Preparation of antispectrin antibody. Antispectrin was prepared in rabbits directly from minces of gel electrophoresispurified spectrin. After partial purification of the antibody by separation of the IgG fraction with $\mathrm{NH}_{4} \mathrm{SO}_{4}$ precipitation, it gave a single line of identity with purified spectrin in an immunodiffusion assay. Through the generosity of Dr. Joyce Geiduschek of the University of California, San Diego, Calif., it was compared with a similar antibody prepared there in the laboratory of S. J. Singer. In terms of both its specificity and the eventual fluorescent staining of spectrin in mouse erythrocytes, nearly identical results were obtained with both antibodies. Fluorescinated caprine antirabbit antibody for counterstaining was obtained from the Pasteur Institute (Garches, Institute) and used without further purification.

\footnotetext{
${ }^{1}$ Abbreviation used in this paper: PBS, phosphate-buffered saline.
} 


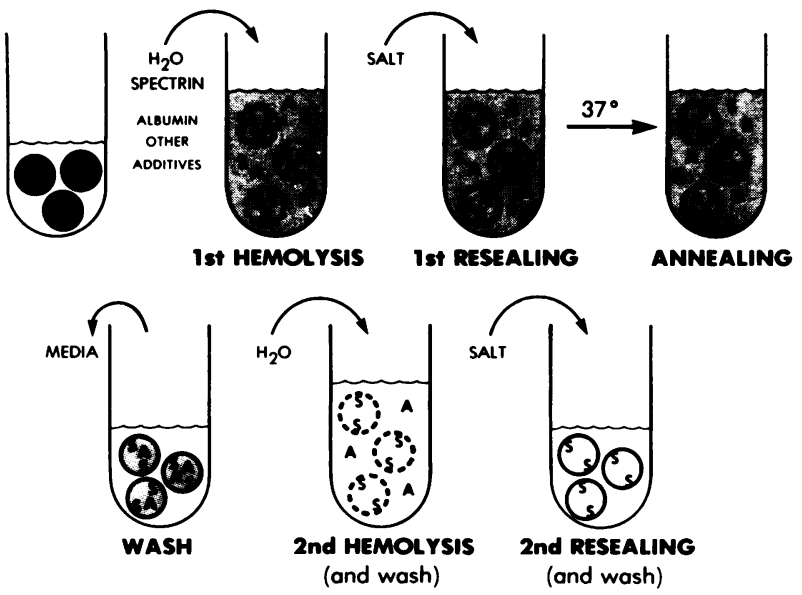

FIGURE 1 Schema of reconstitution system. Spectrin and other additives are incorporated within the erythrocyte membranes by exchange hemolysis and subsequent salt-mediated resealing. Adherence of spectrin occurs after an annealing step with incubation at $37^{\circ} \mathrm{C}$. Subsequent washes and a second hemolysis and resealing step serve to remove nonspecifically trapped additives. Please see Methods for further details.

Reincorporation of spectrin by exchange hemolysis. (Please see Fig. 1.) Reconstituted ghosts were obtained by hypotonic lysis of erythrocytes in the presence of purified dialyzed spectrin. In general, this procedure represented a modification of the method developed by Dr. Margaret Clark for preparing hybrid erythrocytes in sickle cell disease (31).

Washed erythrocytes were hemolyzed at $0{ }^{\circ} \mathrm{C}$ for $10 \mathrm{~min}$ in $40 \mathrm{vol}$ of a lysing solution containing $5 \mathrm{mM}$ potassium phosphate buffer at pH 6.2, $0.25 \mathrm{mM}$ ATP, $1.0 \mathrm{mM}$ calcium chloride, $0.25 \mathrm{mM}$ magnesium chloride, and various amounts of either labeled purified spectrin, ${ }^{2}$ heat-denatured spectrin, hemoglobin, or ${ }^{131}$ I-labeled bovine serum albumin. All of these latter macromolecules were dialyzed against large quantities of $0.5 \mathrm{mM}$ phosphate buffer before use. This first hemolysis step is subsequently referred to as the primary lysis.

After primary lysis, the open membranes were resealed to entrap the macromolecules by the addition of isotonic potassium chloride while still at $0^{\circ} \mathrm{C}$. The temperature was then raised to $37^{\circ} \mathrm{C}$ to allow binding of spectrin to the interior surface of the resealed membranes and to facilitate any potentially important membrane rearrangements. This step, which was found to be necessary, has been termed the "annealing" step. Subsequently, the external media containing untrapped added macromolecules was removed by washing with PBS.

After this intermediary wash, the cells were lysed a second time with the lysis media without macromolecular additives to release any unbound spectrin passively trapped during the first resealing operation. After two subsequent washes with lysing solution, the ghosts were finally resealed for a second time with potassium chloride, washed, and used for assay.

Varying concentrations of salt were used for resealing and various times for annealing in the initial phases of this work

${ }^{2}$ In addition to using [ $\left.{ }^{32} \mathrm{P}\right]$ spectrin labeled in whole cells, when higher specific activity was desired, ${ }^{131}$ I-labeled spectrin, prepared from our column-purified material using the lactoperoxidase-glucose oxidase method (34), was utilized. No differences in the behavior of these two preparations were seen. (vide infra). However, eventually a standardized resealing solution of $145 \mathrm{meq} \mathrm{KCl}$ and a standard annealing time of $30 \mathrm{~min}$ were used.

Sham-reconstituted membranes were prepared as in the normal preparation, except that spectrin was omitted from the initial lysing solution. Because it was impossible to maintain sham-reconstituted membranes of spectrin-deficient cells for more than a few minutes after the initial resealing step, the experiments described below using stop-flow analysis to study cell swelling were limited to preparations completed after only $15 \mathrm{~min}$ of annealing after initial resealing.

Fluorescent staining. To identify mouse spectrin by fluorescent staining, a suspension of erythrocytes in saline at $\sim 0.2 \%$ hematocrit was allowed to settle for $20 \mathrm{~min}$ on clean polylysine-treated cover slips. The excess cell suspension was drained free, and the cover slips were washed by gentle immersion in PBS and fixed with $3 \%$ formaldehyde in PBS at pH 7.4 for $15 \mathrm{~min}$. After fixation, they were washed once with PBS containing $0.1 \mathrm{M}$ glycine to neutralize the fixative, and then by two additional PBS washes. To obtain membrane permeability to the antibodies, the cover slips were then exposed to $0.1 \%$ Triton in PBS for $5 \mathrm{~min}$. After three PBS washes, the primary rabbit antispectrin antibody diluted 600 times was added and the preparations were incubated at $37^{\circ} \mathrm{C}$ for $30 \mathrm{~min}$ followed by three more washes and a second incubation with caprine fluorescinated anti-rabbit antibody diluted 300 times. After four final washes with PBS, the cover slips were inverted and mounted with $85 \%$ glycerol.

Myelin figure and "fusion complex" assays. Myelin figures were induced in spherocytic mouse cells by treating a $20 \%$ hematocrit suspension in $300 \mu \mathrm{g} / \mathrm{mg}$ defatted bovine albumin, $5 \mathrm{mM}$ glucose, and $20 \mathrm{mM}$ phosphate buffer at $\mathrm{pH} 7.4$ with 0.1 $\mathrm{mM}$ lysolecithin for $0.5 \mathrm{~h}$ at $37^{\circ} \mathrm{C}$. Dilutions of this suspension were then made to give a slide preparation containing $\sim 30$ cells/ high-powered field, and 50 consecutive high-power fields were counted by use of a Nomarski phase microscope and plastic cover slips to reduce spontaneous echinocytogenesis in normal cells. Fusion complexes were defined as two immediately adjacent cells forming a figure-8 configuration with no sharp demarcation at the contiguous surfaces. On occasion, under observation in the phase microscope, these units could be seen to change rapidly to a single, larger round cell. Some of these, in turn, hemolyzed, whereas others remained stable for some time. Fusion complexes were prepared in the same manner as the myelin figures, except that the cell suspension was initially loosely packed by a 2 -min centrifugation at $5,000 \mathrm{~g}$ to facilitate contact between cells during the incubation.

Lipid loss measurements. To study lipid loss as a representation of membrane loss in various cell and reconstituted cell preparations, the initial starting cells were briefly labeled with radioactive $\left[{ }^{14} \mathrm{C}\right]$ palmitic acid following methods previously described (35). After removing unbound radioactive fatty acid with three PBS washes, the erythrocytes were either used to prepare reconstituted membranes or reserved for use as nonreconstituted controls. The actual assay was then performed by incubating the untreated control and the reconstituted cells in media consisting of 540 mosmol sodium chloride, $5 \mathrm{mM}$ glucose, and $20 \mathrm{mM}$ phosphate buffer at $\mathrm{pH}$ 7.4. Aliquots were removed at various times, and spun in a microcentrifuge at $12,000 \mathrm{~g}$ for $2 \mathrm{~min}$ to collect the intact cell membranes. The top $80 \%$ of the supernate containing sinall fragments of shed membrane material was carefully removed and counted for radioactivity. On two occasions, sufficient samples were pooled to enable determination of the total "lipid specific activity" (counts per minute per microgram lipid phosphorus) of the supernatant material in comparison to the bottom material from the bulk of the cells. The specific activities of the whole cells and the membrane frag- 
ments were virtually the same, and it was assumed that the released lipid was representative of the starting membrane lipid.

Kinetic studies of osmotic swelling of intact cells and resealed membranes. For these studies a suspension of $\sim 3 \%$ hematocrit of erythrocytes or reconstituted ghosts containing hemoglobin and albumin as well as spectrin, was prepared in 300 mosmol PBS. Immediately after resuspension to minimize settling, these cells were added to an Aminco-Morrow stop-flow analysis apparatus connected to a microprocessor, a large computer memory, and a cathode ray tube display (36). The cell suspension was then very rapidly diluted by an equal volume of $50 \mathrm{mosM}$ saline to produce a final osmolarity of 175 mosmol. The reduction in the light transmission caused by both light scattering and absorption over the next $100 \mathrm{~ms}$ was measured using a visible light detector at $550 \mathrm{~nm}$ and at maximum slit width $(5 \mathrm{~mm})$ without further filtering. The kinetics of these signals were preserved through the computer, and subsequently displayed on the cathode ray tube from which the patterns were traced.

For these studies, reconstituted cells were prepared with $100 \mu \mathrm{g} / \mathrm{ml}$ of spectrin in the original exchange hemolysis as well as $50 \mathrm{mg}$ of dialyzed human hemoglobin and $50 \mathrm{mg}$ of dialyzed bovine serum albumin/ml of lysis media. These last agents were added to increase the oncotic contents of the resealed cells, and to supply some color for the subsequent kinetic analysis of hemolysis.

Other methods. Sodium dodecyl sulfate polyacrylamide gel electrophoresis analysis was performed with a 5-15\% gradiant as described by Laemmli (37). Protein determination was performed by the Lowry technique (38). The specific activity of membrane lipids was estimated from the same lipid extract which was both counted for radioactivity and subsequently analyzed for total phosphorus on microchromatography plates $(39,40)$. The extent of spectrin incorporation in the various incubations was determined from measurements of the radioactivity of the added spectrin of known specific activity divided by the total protein (38) of the membrane preparations remaining after the last washing procedure.

\section{RESULTS}

Concentration dependence of spectrin reconstitution. Fig. 2 is a photograph of sodium dodecyl sulfate polyacrylamide gel electrophoresis analysis of the membranes of spherocytic mouse erythrocytes (Sph membranes) which have been reconstituted with varying amounts of normal mouse spectrin. The samples were obtained after the second hemolysis and washes. An effort was made to plate approximately the same amount $(10 \mu \mathrm{g})$ of total membrane protein in each of the electrophoresis wells. With increasing amounts of spectrin added during the first hemolysis, increasing amounts of bound spectrin were isolated after the last hemolysis. Other membrane proteins, including actin which was present in normal amounts, appeared to be unchanged. Fig. 3 quantitates this observation more completely, and shows that spectrin which had been denatured by heating before incorporation did not adhere in the same manner to the spherocytic membranes. In data not shown here, considerable entrapment of denatured spectrin - though not to the extent of unheated spectrin-did occur during the first resealing.

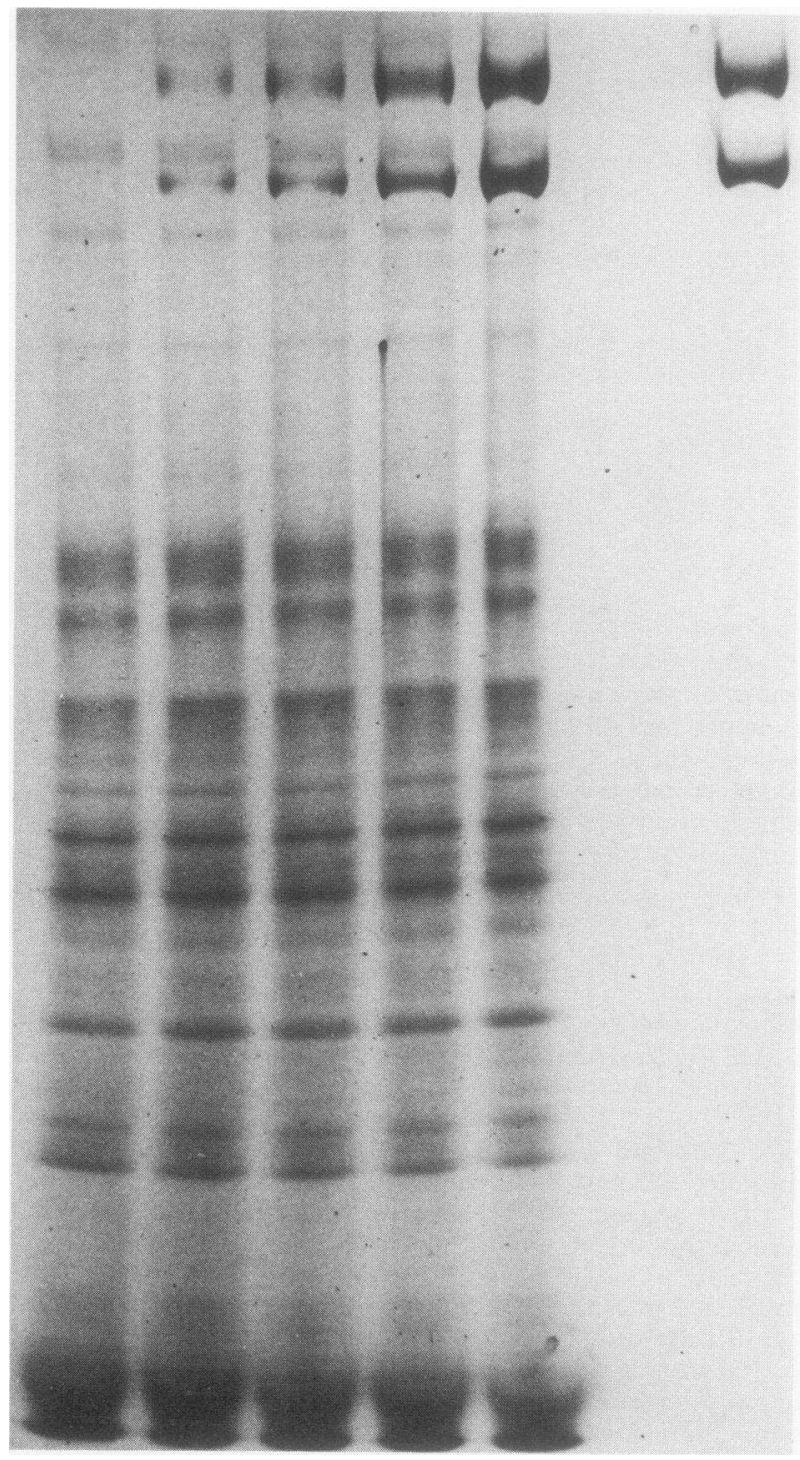

Figure 2 Sodium dodecyl sulfate polyacrylamide gel electrophoresis of membranes from spherocytic mice reconstituted with progressive amounts of purified mouse spectrin. Band A, control membranes without reconstitution. Bands B-E, spherocytic mouse membranes reconstituted with $10,20,50$, and $150 \mu \mathrm{g}$, respectively, of spectrin/ml of original reconstitution media. Approximately $10 \mu \mathrm{g}$ of total membrane protein was placed in eash well. Band F, purified mouse spectrin used for the reconstitution; $2 \mu \mathrm{g}$.

However, the vast majority of this material was released in the second lysis and washes. It should be noted that the maximum concentrations of spectrin which can be bound to the membrane under these conditions $(\sim 125 \mu \mathrm{g} / \mathrm{mg}$ membrane protein) is only $\sim 60 \%$ of normal levels in the mouse membrane. This is also somewhat lower than the levels achieved with spectrin-depleted inside-out vesicles (32). Finally, this figure shows that even fresh spectrin does not bind to 


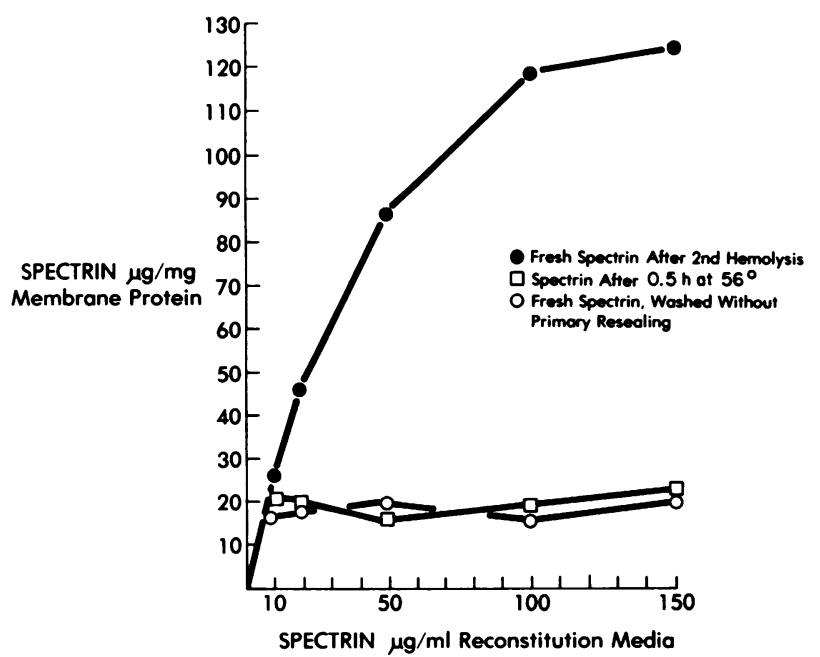

FIgURE 3 Concentration dependence of reconstitution. The original hemolyzate contained $0.25 \mathrm{mM}$ ATP, $0.25 \mathrm{mM} \mathrm{MgCl}_{2}$, and $1.0 \mathrm{mM} \mathrm{CaCl}_{2}$, as well as fresh or heat-denatured spectrin at the concentrations indicated. Both fresh (O) and heat-denatured spectrin $(\square)$ were analyzed after the full reconstitution system, including the annealing step. The open circles indicate the results of an incubation with fresh spectrin which was analyzed before the primary resealing step.

the Sph membranes when the cells are promptly washed with low ionic strength media before resealing has occurred.

Ionic strength dependence of reconstitution. A marked sensitivity to ionic strength in the process of spectrin binding to Sph membranes is seen in Fig. 4. Approximately $50 \%$ levels of binding were obtained

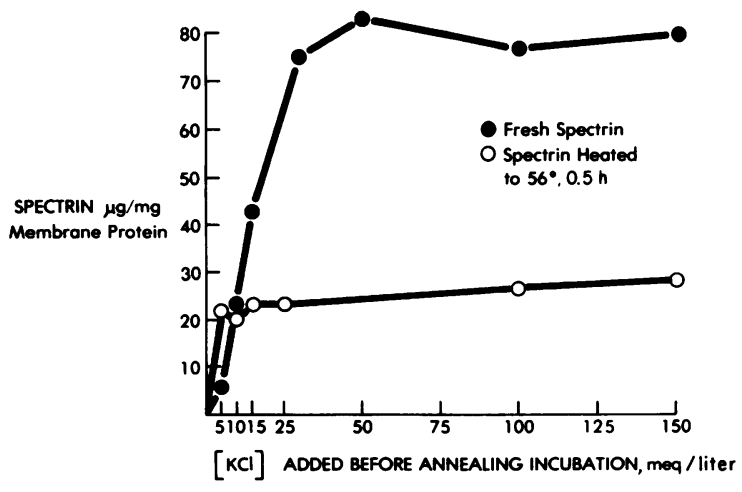

FIGURE 4 Ionic strength dependence of reconstitution. Incubation media contained the same additives as in Fig. 3, except for the spectrin which was standardized in all cases at $\mathbf{5 0}$ $\mu \mathrm{g} / \mathrm{ml}$ or original hemolysis media.

with 30 meq of total ions. In data not shown here, sodium chloride was as effective as potassium chloride for this process. Heated spectrin showed very little ionic strength-dependent binding in this system. Although the data presented here only present results for an initial spectrin concentration of $50 \mu \mathrm{g} / \mathrm{ml}$ in the original hemolyzate, similar results were obtained with 150 and $20 \mu \mathrm{g} / \mathrm{ml}$.

Time dependence for reconstitution. Fig. 5 shows the need for some time to pass after the initial resealing step and before the second hemolysis for spectrin to bind completely to the Sph membranes. In this study, performed at an initial concentration of $50 \mu \mathrm{g} / \mathrm{ml}$ of spectrin in the original hemolyzate, $50 \%$ levels of binding were obtained $\sim 6 \mathrm{~min}$ after resealing, and the proc-

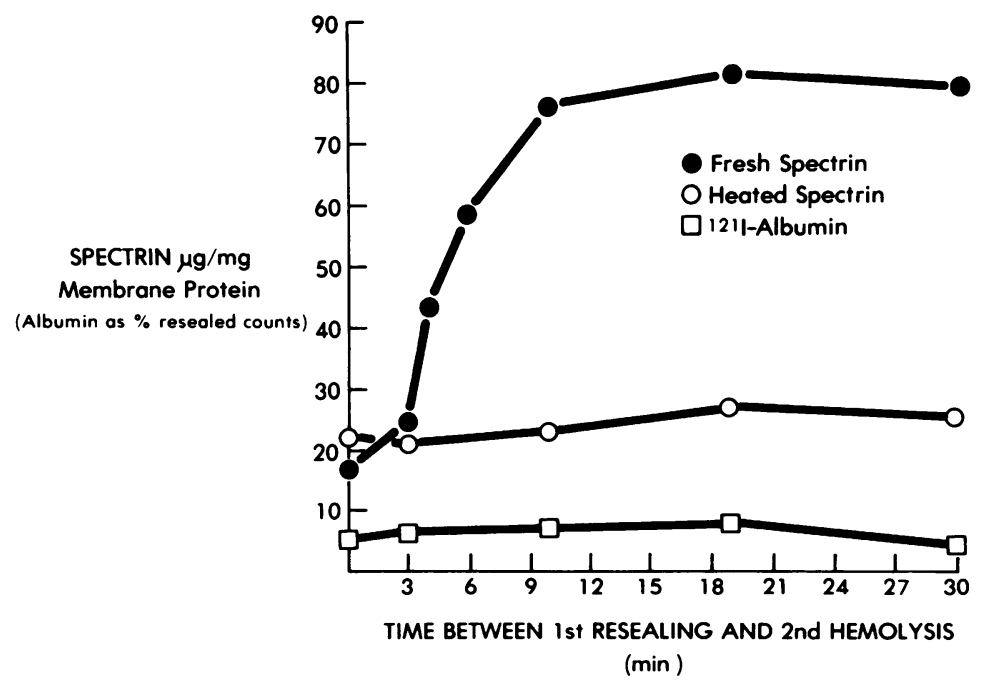

FIgURE 5 Time dependence for reconstitution. The incubations were carried out with the same additives as in Fig. 3 with $50 \mu \mathrm{g}$ of spectrin $/ \mathrm{ml}$ of original hemolyzate and with the addition of $50 \mu \mathrm{g} / \mathrm{ml}$ of radioactively labeled albumin. The time between the initial resealing step and the second hemolysis was varied by reducing annealing time. The first 3-min point represents the minimal time needed for the washing step. 
ess was not complete until somewhat after $10 \mathrm{~min}$ following resealing. Again, the retention of denatured spectrin was much reduced and was not influenced by the time after the initial resealing. Apparently some initial nonspecific adherence of both fresh and heated spectrin to the membrane occurred at 0 time, but there was virtually none of this effect for albumin which was also used as a control in this experiment.

Immunofluorescent studies. Fig. $6 a$ and $b$ present photographs of native and reconstituted mouse spherocytes treated with the fluorescent antispectrin antibody system after Triton X-100 (Rohm \& Haas Co., Philadelphia, $\mathrm{Pa}$.) treatment to facilitate membrane permeability. In Fig. $6 a$ virtually no specific staining is seen in a preparation of native hereditary spherocytes. In Fig. $6 b$ intense staining is found in spherocytes which have been reconstituted with normal spectrin and then relysed and washed to remove passively trapped spectrin. In experiments not shown here, con-
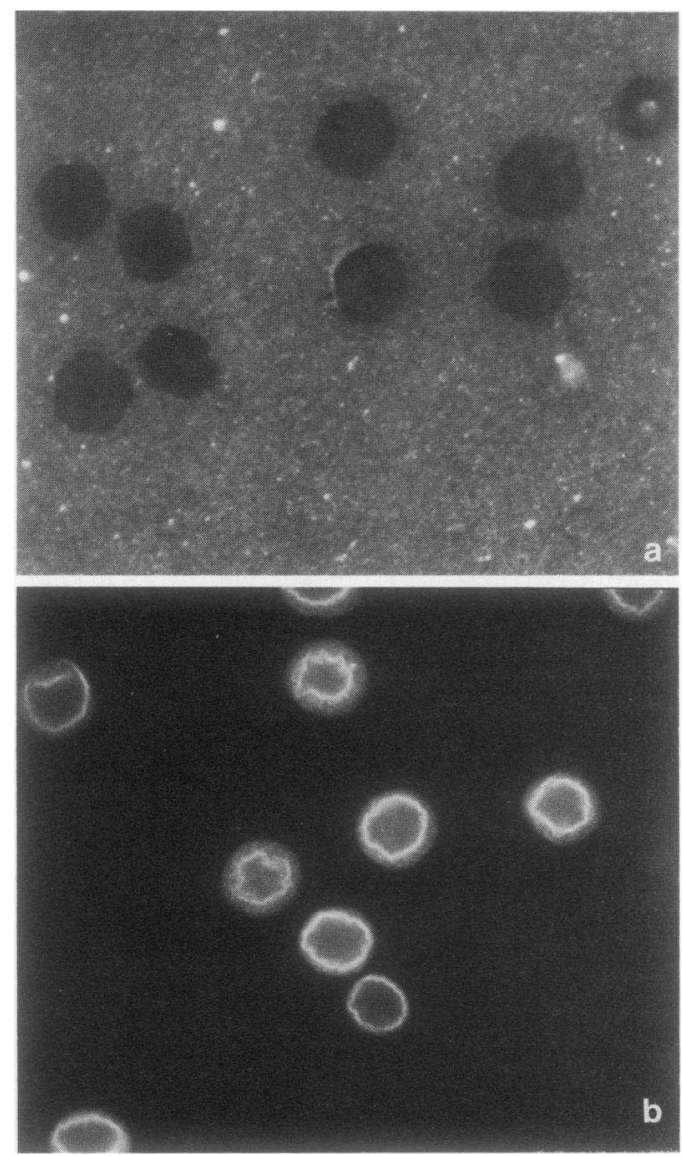

FIGURE 6 Fluorescent photomicrographs of native $(a)$ and reconstituted $(b)$ mouse spherocytes. Cells were attached to polylysine treated glass slides and stained with antispectrin antibody after Triton treatment of fixed cells to facilitate antibody permeation. Please see Methods for further detail trols with nonspecific rabbit IgG instead of the antispectrin antibody showed little labeling with either preparation, whereas omitting either Triton or the antispectrin antibody completely eliminated the labeling. Finally, it should be noted that the reconstituted cells unfortunately continued to have the appearance of collapsed spheres. Adding spectrin back to these membranes did not tend to produce bi-concave disks under these conditions.

Membrane fragility and lability studies. Fig. 7 a and $b$ demonstrate the myelin figures and fusion complexes which can be produced by incubation of Sph cells in hypertonic media in the presence of small amounts of lysolecithin. Normal mouse erythrocytes incubated under the same conditions showed virtually no changes.

A quantitation of this phenomenon and the effect of reconstitution with fresh spectrin is shown in Fig. $8 a$ and $b$. The production of myelin figures was markedly reduced after reconstitution of the Sph cells, whereas reconstitution of normal cells expectedly showed no effect. Similarly, fusion complexes which were not uncommon in the untreated intact spherocytes were markedly reduced after reconstitution, and they were extraordinarily rare in both normal and sham-reconstituted normal cells. It should be noted that it was unfortunately impossible to study sham-reconstituted Sph cells in this system, because they could not be preserved during the 0.5 -h hypertonic incubation in the presence of lysolecithin.

Lipid loss in native and reconstituted spherocytes. Fig. 9 shows the effect of incubation of those cells in hypertonic media containing lysolecithin. Because the relative lipid specific activity of the starting cells and the released lipid were similar, the palmitic acid label used here was assumed to be representative of the general lipid moiety of the membrane. Untreated Sph membranes showed an appreciable lipid loss of $\sim 15 \%$ of their total starting label into the media during incubation. This loss was considerably reduced after reconstitution with mouse spectrin. Normal mouse cells, as well as sham-reconstituted normal mouse cells, showed very little lipid loss under these conditions.

Stop-flow analyses of the kinetics of osmotic swelling of intact Sph and normal mouse cells. Fig. 10 shows the signal obtained after the very rapid application of osmotic shock to normal and Sph mouse erythrocytes. The normal curve indicated by the dotted line shows two phases. The first, which may primarily represent changes in light reflection caused by cell swelling, had a half-time of $\sim 15 \mathrm{~ms}$; the second, which probably represents the release of hemoglobin from the lysing cells, had an extrapolated half-time of $\sim 40 \mathrm{~ms}$. Lysis of intact hereditary spherocytes under the same conditions proceeded much more rapidly and in a single phase with an overall half-time of $\sim 7 \mathrm{~ms}$. 

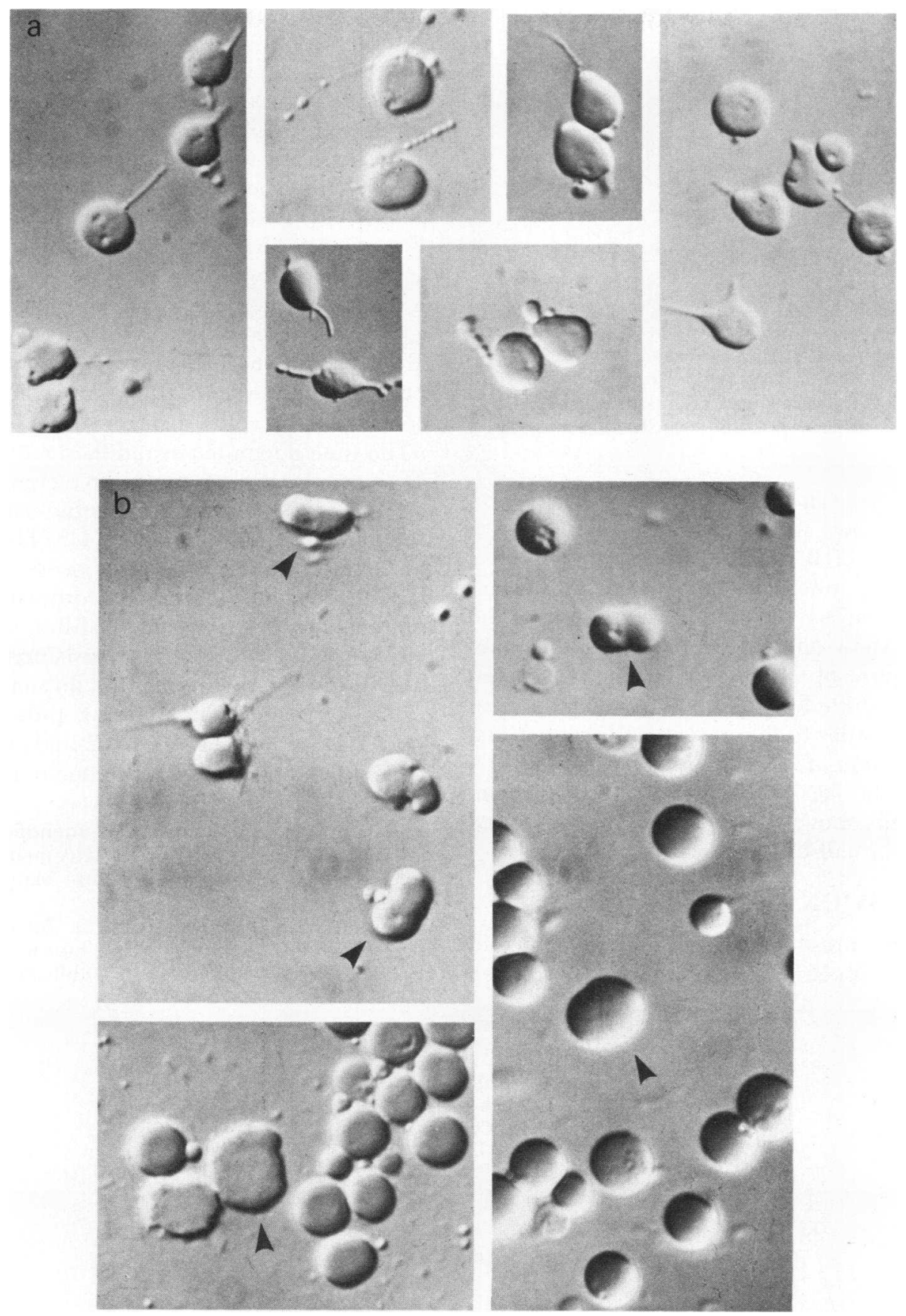

Figure 7 Myelin figures $(a)$ and fusion complexes $(b)$ in native spherocytes in vitro. Unfixed cells examined with Nomarski phase optics after incubation of fresh cells in hypertonic (540 mosmol) sodium chloride with $300 \mathrm{mg} \%$ defatted bovine albumin, $5 \mathrm{mM}$ glucose, $20 \mathrm{mM}$ phos-

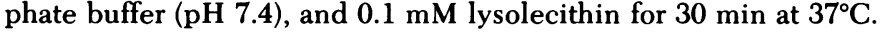

Stop-flow analysis of the kinetics of osmotic swelling of resealed reconstituted membranes. Fig. 11 shows a similar osmotic shock experiment performed on reconstituted membrane preparations. Note that the coordinates are different from the previous data, because the hemolysis proceeded at a different rate, and because the hemoglobin concentration of the reconstituted cells, which was arbitrarily set at $50 \mathrm{mg} / \mathrm{ml}$ of packed cells by the lysis conditions, gave different signals in the stop-flow apparatus. Normal cells which were sham-reconstituted (indicated by the dashed line) again show a two-phase curve which is reminiscent of 


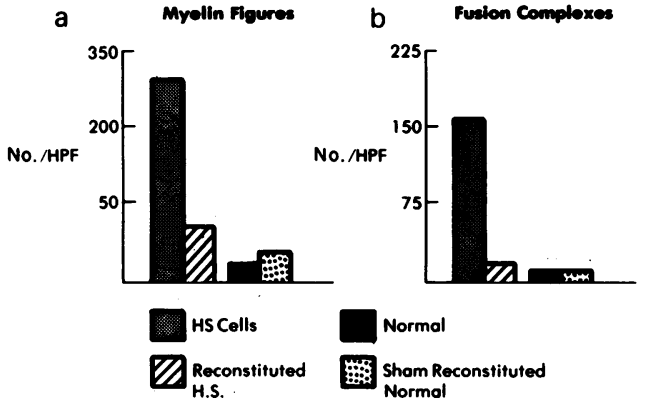

Figure 8 Quantitation of myelin figures and fusion complexes. Native and reconstituted spherocyte membrane cells were incubated as in Fig. $7 a$ and $b$. Numbers of myelin figures and fusion complexes per high-powered field $(H P F)$ are indicated in active and reconstituted hereditary spherocytes (H.S.) and in normal and sham-reconstituted normal cells.

normal whole cells. The half-time of the first phase of the curve is now $\sim 15 \mathrm{~ms}$, and the half-time of the second phase of the curve, by extrapolation, is $\sim 60 \mathrm{~ms}$. Hereditary spherocyte cells which were shamreconstituted as far as the first resealing step (the unbroken line), show only one rapid swelling component with a half-time of $\sim 10 \mathrm{~ms}$. Spectrin-reconstituted spherocytes (the dotted line) show a two-component curve which is similar to the normal cells with a first component half-time of $\sim 15 \mathrm{~ms}$ (although apparently without the slight lag period which normal shamreconstituted cells show in this system), and a second component with a half-time of $\sim 25 \mathrm{~ms}$.

\section{DISCUSSION}

The experiments presented here are analogous in several respects to spectrin rebinding studies conducted by Bennett and Branton with inside-out vesicles obtained from spectrin-depleted human erythrocyte membranes (32). Although there are moderate differences in the total amount of spectrin which could be bound as well as in the amount of salt necessary to facilitate this binding, the similarities in the requirement for time to pass during the binding process, the saturable concentration dependence, and the ineffectiveness of heated spectrin are all closely analogous (Figs. 2-5). The fact that spectrin reconstitution to only $50-60 \%$ levels has such profound effects on the in vitro characteristics of the reconstituted cells suggests either that a little spectrin can have a large biologic effect, or that the difference between the binding of intact membranes and inside-out vesicles may involve a portion of the cell's spectrin which is not functional.

The time dependence and the ionic strength effects of spectrin binding appear to be reciprocally analogous to the conditions necessary for the extraction of spectrin from whole membranes (41). This suggests that the extraction and binding process is reversible in normal cells, and implies that fortunately the putative binding site for spectrin is still intact in spectrindeficient hereditary spherocytosis erythrocytes. However, the current experiments do not shed any light on the nature of that binding protein which is of considerable current interest (42, and footnotes 3 and 4 ).

The immunologic demonstration of fluorescent label-

${ }^{3}$ Bennett, V., and J. Stenbuck. Identification and partial purification of ankyrn, the high affinity membrane attachment site for human erythrocyte spectrin. Manuscript submitted for publication.

${ }^{4}$ Yu, J., S. R. Goodman, and D. Branton. Nectins: the spectrin-binding protein(s) of the human erythrocyte membrane. Manuscript submitted for publication.

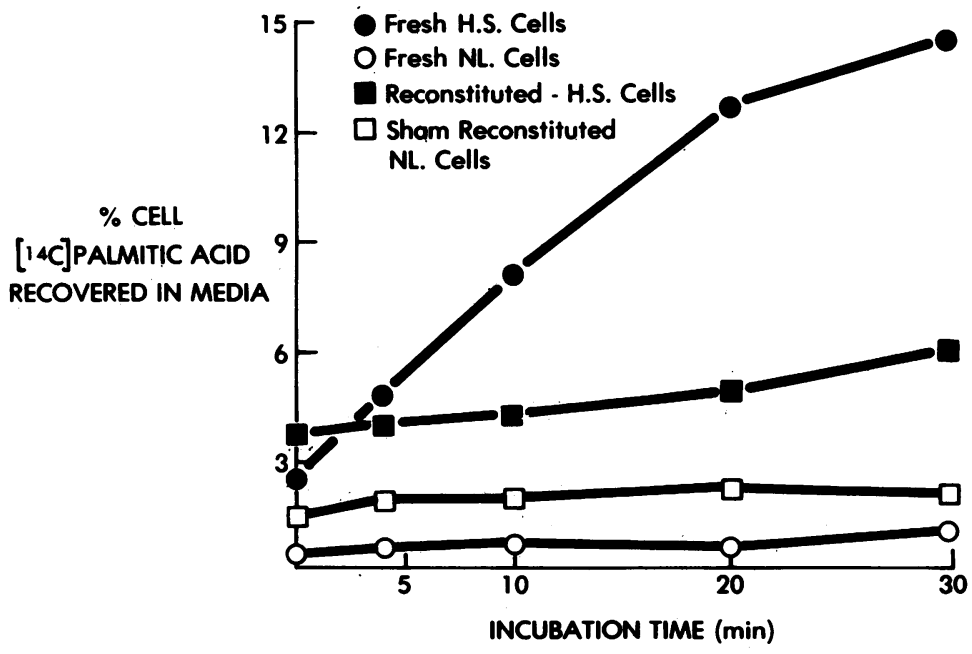

FIGURE 9 Lipid loss measurements. $\left[{ }^{14} \mathrm{C}\right]$ palmitic acid and prelabeled cells were incubated in 540 mos $M$ sodium chloride, $5 \mathrm{mM}$ glucose, and $20 \mathrm{mM}$ phosphate buffer (pH 7.4). After rapid centrifugation, aliquots of the reincubation media were counted for radioactivity. The results are presented as percent of original cell counts found in the media. H.S., hereditary spherocytosis; NL., normal. 


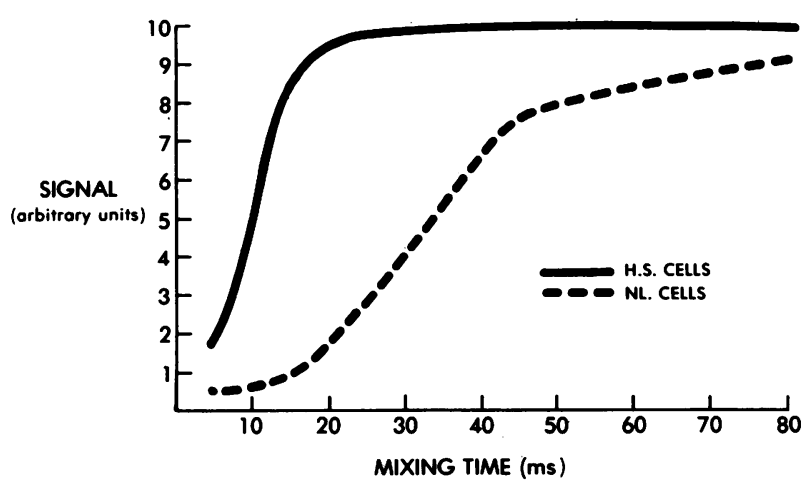

FIgURE 10 Rapid kinetic studies of osmotic swelling of intact cells. The suspension of cells in saline was rapidly mixed with an equal volume of $50 \operatorname{mos} M$ saline to induce osmotic shock. The resulting change in light scattering and transmission caused by cell swelling and hemoglobin release was recorded in a high-speed stop-flow apparatus. The data are presented as arbitrary units of the response of the photodetector of that apparatus during the first $80 \mathrm{~ms}$ after mixing. H.S., hereditary spherocytosis; $N L$., normal.

ing of spectrin-reconstituted cells with specific antispectrin antibody (Fig. $6 \mathrm{~b}$ ), and not with the native spherocytes (Fig. $6 a$ ) or nonspecific rabbit IgG, is partial evidence for a specific attachment of spectrin during the reconstitution maneuvers. The fact that denatured spectrin and albumin did not form a permanent attachment to the membrane interior (Figs. 3-5) also supports this conclusion. However, conclusive specificity of the rebinding process is not absolutely proven by either of these observations or even the strong analogies to the depleted vesicle-rebinding studies. Remotely, saturation of nonspecific binding sites might occur in these artificial conditions which would be difficult to distinguish from physiologic or native binding. Similarly, the ionic dependence and the ineffectiveness of denatured spectrin might also possibly be found in a nonspecific binding process. Unfortunately, without further fundamental information regarding the intimate mechanisms of the binding process (eg., isolation of the native binding site or sites), this ambiguity will remain. Nevertheless, such difficulties in ultimate interpretation do not appreciably weaken the power of these observations in implying a role for spectrin in regulating erythrocyte function. Whatever its mechanism, the adherence of spectrin we have observed appears to have a strong influence on erythrocyte behavior.

The prevention of the formation of myelin figures (Fig. $8 a$ ) and the prevention of lipid loss (Fig. 9) by the binding of spectrin to the Sph membranes strongly suggest a membrane-stabilizing role for this molecule. It is of interest to note that it was necessary to incubate the cells in hypertonic media to demonstrate these phenomena in the nonreconstituted cells. In media of normal osmotic strength, the nonreconstituted controls lysed extremely rapidly without passing through any

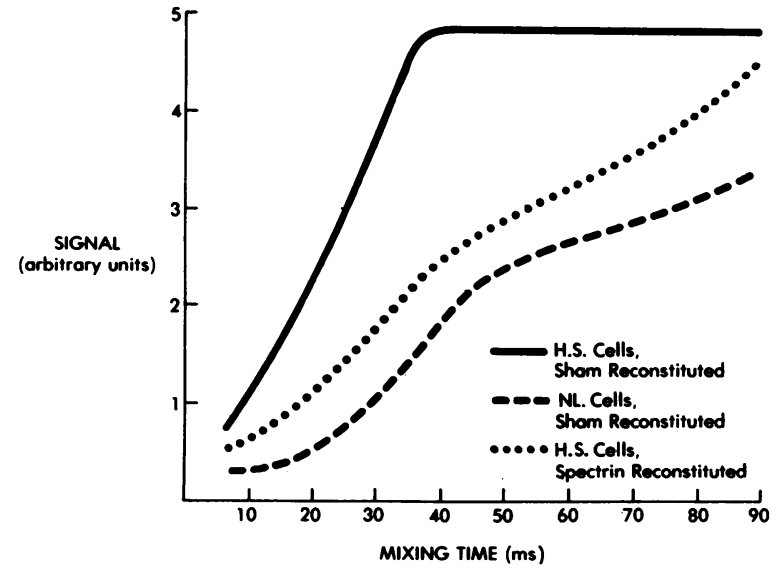

FIGURE 11 Rapid kinetic studies of osmotic swelling of resealed reconstituted membranes. Experiments similar to those with intact membranes were conducted with various reconstituted preparations. The mixing conditions were the same, but the arbitrary height of the signal was modified because of the reduced hemoglobin levels and the mixing time was followed for $90 \mathrm{~ms}$. Please see Materials and Methods for further details. H.S., hereditary spherocytosis; NL., normal.

visible membrane-loss phase. It is likely that the hypertonic conditions produced some moderate amount of membrane reserve, in that cell volume was immediately reduced before membrane surface began to be lost. This interpretation is further suggested by the observation that spherocytes incubated under these hypertonic conditions, when returned to isotonic media, promptly lysed. In fact, in experiments to be presented in detail elsewhere, an estimation for the loss of cell surface area which occurred during hypertonic incubation could be obtained by determining the minimum hypertonicity necessary for membrane stability after such incubation, and assuming spherical geometry at that point. Interestingly, this estimate of cell surface loss closely paralleled the biochemical determination of lipid loss shown in Fig. 9.

The prevention of apparent fusion complexes by the insertion of spectrin into Sph membranes is of considerable interest. Previous studies in liposome model systems have shown similar effects of spectrin $(27,43)$. Perhaps a spectrin meshwork prevents the formation of large protein-free lipid regions, or domains, necessary for fusion. Alternatively, perhaps association of spectrin with the anionic phospholipids, phosphatidyl ethanolomine and phosphatidyl serine, keeps them localized to the inner leaflet of the membrane $(27,28,44)$ and prevents their requisite participation in fusion events which one would expect initiate at the outer surface. To explore these possibilities, we have tried to determine the "sidedness" of the lipids in these spherocytes, but so far all efforts to treat the cells with tri nitro benzine sulfonate or phospholipases have produced immediate lysis of the native spherocytes, vitiating the usefulness of this type of data. 
A note of caution is in order in terms of interpreting the apparent fusion complexes seen here. Although the appearance of fusion shown in Fig. $6 b$ is not infrequent, rigorous proof of fused membranes rather than a simple intimate contact has not been obtained even though the apparent fusion process itself, with loss of the central band and the appearance of a somewhat larger spherical cell, was occasionally directly observed.

The observations shown in Figs. 10 and 11 indicate that the osmotic responsiveness of the erythrocytes is also regulated in part by spectrin. Unfortunately, the technique of stop-flow analysis is not currently sensitive enough to define the precise mechanism of this effect. From the previous studies of Sha'afi et al. (45), it has been suggested that the early phase swelling curve is primarily caused by a rounding up of the cells and the change in light reflectance produced by this phenomenon, whereas the second phase is probably related primarily to the release of hemoglobin from the lysing erythrocytes. Theoretically, a brief plateau phase should occur between these two components where membrane stretching actually occurs. If the system could be sufficiently refined to demonstrate this interval, a much more precise definition of spectrin's role might be possible. However, with current resolution, it is difficult to propose a mechanism for even the initial swelling phase, because it is not known if the fabric of the membrane has any role in mechanically resisting the influx of water during this period or, alternatively, if spectrin induces any change in limiting water permeability of the membrane which secondarily affects the swelling rate. Nevertheless, in spite of limitations in precise interpretation, this technique does allow the assignment of an unequivocal role for spectrin in changing the osmotic response of erythrocyte membranes; and this technique, which has seen little use by cell biologists or hematologists, is to be recommended.

Finally, a comment should be made concerning the fact that $0.25 \mathrm{mM}$ ATP and $0.25 \mathrm{mM}$ magnesium were added to all of the reconstitution studies described here. This was arbitrarily done in an effort to preserve the phosphorylated state of spectrin as much as possible, and to facilitate any residual ATP-dependent membrane processes which might be important for stabilizing these difficult in vitro preparations. At present, it is not known whether or not this ATP is essential. Preliminary results do show that spectrin in reconstituted spherocyte membranes is capable of being phosphorylated by $\left[{ }^{32} \mathrm{P}\right] A T P$. Studies on the role of ATP and, in particular, on the importance of the phosphorylation state of spectrin should be of considerable interest.

The hereditary spherocytosis syndrome of mice appears to be an excellent model for studying the func- tional role of spectrin. Even though neither the biochemical nor the genetic mechanism for the production of the spectrin deficiency in these cells is presently known, the fact that these cells have markedly perturbed biologic behavior has supported hypotheses for an important functional role of spectrin in the erythrocyte membrane. The current experiments in which the missing protein has been reinserted into the membrane have facilitated the direct testing of these hypotheses and have permitted an assignment of some specific functional roles for spectrin in the erythrocyte membrane.

In particular, it appears that spectrin is indeed responsible for stabilization of the membrane and prevention of membrane loss through myelin figure formation and membrane lipid loss. Moreover, spectrin appears to prevent membrane fusion which is a very rare occurrence in normal cells, but which is surprisingly common in hereditary Sph spherocytes. Finally, spectrin appears to have an important role in modulating the early response to osmotic swelling in erythrocytes.

\section{ACKNOWLEDGMENTS}

The author is particularly grateful for the kind hospitality of the laboratories of S. J. Singer at the University of California, San Diego, and Marcel Bessis at the Hôpital Bicêtre in Kremlin Bicêtre, France, in which many of these studies were conducted, and to Dr. Sheldon Bernstein of the Jackson Memorial Laboratories at Bar Harbor, Maine, for supplying the spherocytic mice. Dr. Joyce Geiduschek of the Biology Department of the University of California, San Diego, was of great assistance with instruction in, and interpretation of, the immunofluorescent techniques, as was Mr. George Anders in the procurement of mouse blood. The author is also grateful to Dr. Dabney White and Dr. Teddy Traylor, of the Chemistry Department of the University of California, San Diego, for use of their stop-flow apparatus and for instruction in its operation.

The author would like to acknowledge the generous support of the Josiah Macy, Jr. Foundation for a faculty scholar award to pursue these studies while on sabbatical. This work was also partially supported by the National Institutes of Health (grants AM 16095, HD 00254, and RR-00757), as well as the Institut National de la Santé et de la Recherche Medicale.

This is publication No. 1 of The MacMillan-Cargill Hematology Research Laboratory at the University of California, San Francisco, San Francisco, Calif.

\section{REFERENCES}

1. Marchesi, V. T., and G. E. Palade. 1967. Inactivation of adenosine triphosphatase and disruption of red cell membranes by trypsin: protective effect of adenosine triphosphate. Proc. Natl. Acad. Sci. U. S. A. 58: 991-1003.

2. Hiller, G., and K. Weber. 1977. Spectrin is absent in various tissue culture cells. Nature (Lond.). 266: 181-183.

3. Clarke, M. 1971 . Isolation and characterization of a watersoluble protein from bovine erythrocyte membranes. Biochem. Biophys. Res. Commun. 45: 1063-1070.

4. Painter, R. G., M. Sheetz, and S. J. Singer. 1975. Detection and ultrastructural localization of human smooth muscle 
myosin-like molecules in human non-muscle cells by specific antibodies. Proc. Natl. Acad. Sci. U. S. A. 72: 1359-1363.

5. Nicolson, G. L., and R. G. Painter. 1973. Anionic sites of human erythrocyte membranes. II. Antispectrin-induced transmembrane aggregation of the binding sites for positively charged colloidal particles. J. Cell Biol. 59: 395-406.

6. Pinto da Silva, P., and G. L. Nicolson. 1974. Freeze-etch localization of concanavalin A receptors to the membrane intercalated particles of human erythrocyte ghost membranes. Biochim. Biophys. Acta. 363: 311-319.

7. Nicolson, G. L., V. T. Marchesi, and S. J. Singer. 1971. The localization of spectrin on the inner surface of human red blood cell membranes by ferritin-conjugated antibodies. J. Cell Biol. 51: 265-272.

8. Avruch, J., and G. Fairbanks. 1974. Phosphorylation of endogenous substrates by erythrocyte membrane protein kinases. I. A monovalent cation-stimulated reaction. Biochemistry. 13: 5507-5514.

9. Greenquist, A. C., and S. B. Shohet. 1975. Phosphorylation and dephosphorylation in the erythrocyte membrane. In Erythrocyte Structure and Function. G. Brewer, editor. Alan R. Liss, Inc., New York. 515-531.

10. Graham, C., J. Avruch, and G. Fairbanks. 1976. Phosphoprotein phosphatase of the human erythrocyte. Biochem. Biophys. Res. Commun. 72: 701-708.

11. Greenquist, A. C., and S. B. Shohet. 1976. Phosphorylation in erythrocyte membranes from abnormally shaped cells. Blood. 48: 877-886.

12. Sheetz, M. P., and S. J. Singer. 1977. On the mechanism of ATP-induced shape changes in human erythrocyte membranes. I. The role of the spectrin complex. J. Cell Biol. 73: 638-646.

13. Birchmeier, W., and S. J. Singer. 1977. On the mechanism of ATP-induced shape changes in hyman erythrocyte membranes. II. The role of ATP.J. Cell Biol. 73: 647-659.

14. Nakashima, K., and E. Beutler. 1978. Effect of antispectrin antibody and ATP on deformability of resealed erythrocyte membranes. Proc. Natl. Acad. Sci. U. S. A. 75: $3823-3825$.

15. Greenquist, A. C., and S. B. Shohet. 1974. Defective protein phosphorylation in membranes of hereditary spherocytosis erythrocytes. FEBS (Fed. Eur. Biochem. Soc.) Lett. 48: 133-135.

16. Matsumoto, M., Y. Zawta, and H. S. Jacob. 1977. Association of decreased membrane protein phosphorylation with red blood cell spherocytosis. Blood. 49: 233-239.

17. Boivin, P., and C. Galand, 1977. Erythrocyte membrane phosphorylation in hereditary spherocytosis. Biomedicine (Paris). 27: 34-36.

18. Beutler, E., E. Guinto, and C. Johnson. 1976. Human red cell protein kinase in normal subjects and patients with hereditary spherocytosis, sickle cell disease, and autoimmune hemolytic anemia. Blood. 48: 887-898.

19. Wolfe, L. C., and S. E. Lux. 1978. Membrane protein phosphorylation of intact normal and hereditary spherocytic erythrocytes. J. Biol. Chem. 253: 3336-3342.

20. Yu, J., D. A. Fischman, and T. L. Steck. 1973. Selective solubilization of proteins and phospholipids from red blood cell membranes by nonionic detergents. J. Supramol. Struct. 2: 233-248.

21. Lux, S. E., K. M. John, and M. J. Karnovsky. 1976. The membrane defect in irreversibly sickled erythrocytes: Irreversible deformation of spectrin-actin lattice. J. Clin. Invest. 58: 955-963.
22. Palek, J., S. C. Liu, and L. M. Snyder. 1978. Metabolic dependence of protein arrangement in human erythrocyte membranes. I. Analysis of spectrin-rich complexes in ATP-depleted red cells. Blood. 51: 385-395.

23. Lux, S. E., K. M. John, and T. E. Ukena. 1978. Diminished spectrin extraction from ATP-depleted human erythrocytes. Evidence relating spectrin to changes in erythrocyte shape and deformability. J. Clin. Invest. 61: 815-827.

24. Mohandas, N., A. Greenquist, and S. Shohet. 1978. Effects of heat and metabolic depletion on erythrocyte deformability, spectrin extractability and phosphorylation. In The Red Cell, Progress in Clinical and Biological Research. G. Brewer, editor. Alan R. Liss, Inc., New York. 21: 453-472.

25. Greenquist, A. C., S. B. Shohet, and S. E. Bernstein. 1978. Marked reduction of spectrin in hereditary spherocytosis in the common house mouse. Blood. 51: 1149-1155.

26. Shohet, S. B., and A. C. Greenquist. 1977. Possible roles for membrane protein phosphorylation in the control of erythrocyte shape. Blood Cells. 3: 115-133.

27. Momber, C., P. W. M. Van Dijck, L. L. M. Van Deenen, J. DeGier, and A. J. Verkleij. 1977. The interaction of spectrin-actin and synthetic phospholipids. Biochim. Biophys. Acta. 470: 152-160.

28. Haest, C. W. M., G. Plasa, D. Kamp, and B. Deuticke. 1978. Spectrin as a stabilizer of the phospholipid asymmetry in the human erythrocyte membrane. Biochim. Biophys. Acta. 509: 21-32.

29. Tilney, L. G., and P. Detmers. 1975. Actin in erythrocyte ghosts and its association with spectrin. J. Biol. Chem. 66: 508-520.

30. Pinder, J. C., D. Bray, and W. B. Gratzer. 1975. Actin polymerization induced by spectrin. Nature (Lond.). 258: 765-766.

31. Clark, M. R., and S. B. Shohet. 1976. Hybrid erythrocytes for membrane studies in sickle cell disease. Blood. 47: $121-131$.

32. Bennett, V., and D. Branton. 1977. Selective association of spectrin with the cytoplasmic surface of human erythrocyte plasma membranes. Quantitative determination with purified [ $\left.{ }^{32} \mathrm{P}\right]$ spectrin. J. Biol. Chem. 252: 2753-2763.

33. Joe, M., J. M. Teasdale, and J. R. Miller. 1962. A new mutation ( $\mathrm{Sph}$ ) causing neonatal jaundice in the house mouse. Can. J. Genet. Gycol. 4: 219-224.

34. Schenlsein, U., M. Levy, and J. Wuhr. 1972. The use of glucose oxidase as a generator of $\mathrm{H}_{2} \mathrm{O}_{2}$ in the enzymatic radioiodination of components of cell surfaces. Cell. Immunol. 5: 490-493.

35. Shohet, S. B., D. G. Nathan, and M. L. Karnovsky. 1968. Stages in the incorporation of fatty acids into red blood cells. J. Clin. Invest. 47: 1096-1108.

36. White, D. K., J. Cannon, and T. G. Traylor. 1979. A kinetic model for R- and T-state hemoglobin: flask photolysis of heme-imidizole-CO mixtures. J. Am. Chem. Soc. In press.

37. Laemmli, U. K. 1970. Cleavage of structural proteins during the assembly of the head of bacteriophage $T_{4}$. Nature (Lond.). 227: 680-685.

38. Lowry, O. H., N. R. Roberts, K. Y. Leiner, M. L. Wu, and A. L. Farr. 1954. The quantitative histochemistry of brain. I. Chemical methods. J. Biol. Chem. 207: 1-17.

39. Snyder, F., and N. Stephens. 1972. Quantitative carbon-14 and tritium assay of thin-layer chromatography plates. Anal. Biochem. 4: 128-131.

40. Parker, F., and N. F. Peterson. 1967. Quantitative analysis of phospholipids and phospholipid fatty acids from silica gel thin-layer chromatograms. J. Lipid Res. 6: 455-460. 
41. Marchesi, V. T. 1974. Isolation of spectrin from erythrocyte membranes. Methods Enzymol. 32: 275-277.

42. Liu, S. C., and J. Palek. 1978. Physical contacts between spectrin and band 3 in human erythrocyte membrane. $J$. Supramol. Struct. 2: 205. (Abstr.)

43. Portis, A., C. Newton, W. Pangborn, and D. Papahadjopoulos. 1979. Studies on the mechanism of membrane fusion: evidence for an inter-membrane $\mathrm{Ca}^{2+}$-phospholipid complex, synergism with $\mathrm{Mg}^{2+}$, and inhibition by spectrin. Biochemistry. In press.

44. Weidekamm, E., B. Brdiczka, and M. Wildermuth. 1978. Phospholipid composition of human erythrocyte spectrin. Mol. Biol. Rep. 4: 25-28.

45. Sha'afi, R. I., G. Rich, V. W. Sidel, W. Bassert, and A. K. Soloman. 1967. The effect of the unstirred layer of human red cell water permeability. J. Gen. Physiol. 50: 13771399. 